\title{
Post-chemotherapy $T$-cell recovery is a marker of improved survival in patients with advanced thoracic malignancies
}

\author{
MJ McCoy ${ }^{1,2}$, RA Lake',2, RG van der Most ${ }^{1,2}$, IM Dick ${ }^{1,2}$ and AK Nowak ${ }^{*, 1,2,3}$ \\ 'Tumour Immunology Group, School of Medicine and Pharmacology, University of Western Australia, Perth, Western Australia 6009, Australia; ${ }^{2}$ National \\ Centre for Asbestos Related Diseases, Perth, Western Australia, Australia; ${ }^{3}$ Department of Medical Oncology, Sir Charles Gairdner Hospital, Perth, \\ Western Australia 6009, Australia
}

\begin{abstract}
BACKGROUND: There is increasing interest in combining chemotherapy with immunotherapy. However, the effects of chemotherapy on the human immune system are largely unknown.

METHODS: Longitudinal changes in peripheral T-cell subsets in 40 patients with malignant mesothelioma (MM) or advanced non-small cell lung cancer (NSCLC) receiving platinum-based chemotherapy were assessed by flow cytometry and evaluated for associations with clinical outcome.

RESULTS: Proliferating T cells of all subsets were almost entirely depleted at day 8 following chemotherapy, but rapidly recovered above baseline levels. Regulatory T cells (Treg) were most profoundly depleted at this time point. A greater increase in CD8 ${ }^{+} \mathrm{T}$-cell proliferation following one treatment cycle was associated with improved overall survival in univariate (hazard ratio $(H R)=0.40$; $P<0.05)$ and multivariate $(H R=0.17 ; P<0.01)$ analyses. A greater increase in the ratio of $C D 8{ }^{+} T$ cell to Treg proliferation was also predictive of better prognosis.

CONCLUSION: Chemotherapy potentially provides a favourable environment for the development of anti-tumour immunity through transient Treg depletion and regeneration of the T-cell pool. Change in CD ${ }^{+}$T-cell proliferation after one cycle of chemotherapy may represent a useful prognostic indicator in patients with MM and NSCLC.

British Journal of Cancer (2012) 107, I 107-I| I5. doi:10.1038/bjc.2012.362 www.bjcancer.com
\end{abstract}

Published online 21 August 2012

(c) 2012 Cancer Research UK

Keywords: chemotherapy; mesothelioma; non-small cell lung cancer; T cells; prognosis

Palliative chemotherapy with a platinum doublet is the current standard treatment for patients with malignant mesothelioma (MM) and advanced non-small cell lung cancer (NSCLC), with a median survival of approximately 8-12 months in both disease groups (Schiller et al, 2002; Vogelzang et al, 2003; Muers et al, 2008; Scagliotti et al, 2008). Chemotherapy and immunotherapy have traditionally been considered antagonistic treatment options, primarily because of the variable lymphopaenia associated with most cytotoxic drugs. However, over the last decade, preclinical studies have demonstrated that chemotherapy can induce immunogenic tumour cell death, increase antigen presentation and decrease suppressive regulatory $\mathrm{T}$ cell (Treg) populations, resulting in improved anti-tumour immunity (Nowak et al, 2003; Ghiringhelli et al, 2004; Lake and Robinson, 2005; Ghiringhelli et al, 2007; Zitvogel et al, 2010; Rettig et al, 2011). Some chemotherapies have been shown to act synergistically with immunotherapy in animal models (Machiels et al, 2001; Nowak et al, 2003; Zhong et al, 2007; Tseng et al, 2008; van der Most et al, 2009; Anraku et al, 2010; Fridlender et al, 2010). Importantly, we have recently observed that nude mice with a defective T-cell compartment are also deficient in their response to chemotherapy, establishing a direct link between chemotherapy and the immune response (unpublished data).

\footnotetext{
*Correspondence: Professor AK Nowak;

E-mail: anna.nowak@uwa.edu.au

revised 20 June 2012; accepted 17 July 20 I2; published online 21 August 2012
}

Despite growing interest in combining chemotherapy and immunotherapy, little is known of the effects of chemotherapy on the human anti-tumour immune response. An increase in the proportion of total CD4 ${ }^{+} \mathrm{T}$ cells was observed 1 week after infusion of single-agent gemcitabine (Plate et al, 2005), and following each cycle of combination chemotherapy with cisplatin, gemcitabine and 5-fluorouracil (Bellone et al, 2009) in patients with non-resectable pancreatic cancer. In breast cancer, a marked reduction in $\mathrm{B}$ lymphocytes was found in patients undergoing anthracycline-based chemotherapy, whereas the proportion of $\mathrm{CD}^{+} \mathrm{T}$ cells was slightly, but significantly, increased at the end of each treatment cycle (Wijayahadi et al, 2007). However, there has been no comprehensive examination of the effects of chemotherapy on human T-cell subsets and how changes in immunological parameters may impact on the potential for generating antitumour immunity and on clinical outcome.

The aim of this study was to investigate longitudinal changes in the proportion, activation and proliferation of peripheral T-cell subsets in a cohort of patients with MM and advanced NSCLC receiving current standard platinum-based chemotherapy regimens and to assess the prognostic value of observed changes. In light of evidence from animal models (Nowak et al, 2003; Ghiringhelli et al, 2004; Rettig et al, 2011), we hypothesised that chemotherapy would result in an increase in activation and proliferation of $\mathrm{CD}^{+} \mathrm{T}$ cells, the main effectors of anti-tumour immunity and/or a decrease in the suppressive Treg population, and that the degree of change would influence survival and treatment response. 


\section{MATERIALS AND METHODS}

\section{Patient selection}

Eligible patients had a confirmed diagnosis of MM or NSCLC and were planned to receive chemotherapy for advanced or subtotally resected disease as routine clinical care. Other inclusion criteria included age $\geqslant 18$ years and willingness to undergo additional venepuncture at the study site. Exclusion criteria included previous chemotherapy within 3 months, oral/intravenous steroids within $72 \mathrm{~h}$ of study entry, concurrent radiotherapy and known autoimmune disease.

\section{Study design}

Blood samples were collected before cycle 1 day 1 (baseline), 7 days after the start of treatment (cycle 1 day 8 ) and at the end of the first and third treatment cycles (i.e., cycle 1 day 21 and cycle 3 day 21, pre-infusion). Baseline blood samples were obtained before dexamethasone pre-medication was administered. Patients underwent a baseline contrast-enhanced computerised tomography scan of the thorax and upper abdomen before commencing chemotherapy and subsequent follow-up scans as per routine care (after two or three cycles of chemotherapy). Tumour response was determined according to the RECIST criteria for patients with NSCLC (Therasse et al, 2000) or the modified RECIST criteria for patients with MM (Byrne and Nowak, 2004). Best radiological response was classified as the best response achieved from the beginning of treatment to within 3 months of the last chemotherapy cycle. Partial responses were confirmed $\geqslant 4$ weeks later. Baseline demographic and clinical data, including height, weight, disease stage, histological subtype and Eastern Cooperative Oncology Group (ECOG) performance status were collected.

Patients were followed for disease progression and survival until 1 year after enrolment of the last patient. Overall survival was defined as the time from study enrolment to death. Time to progression (TTP) was defined as the time between study enrolment and the date of first observation of radiological progression, unequivocal clinical progression, or death without observed radiological progression.

The study was approved by the institutional Human Research Ethics Committee, and was conducted in accordance with the Declaration of Helsinki and International Conference on Harmonisation Good Clinical Practice guidelines. All patients provided written informed consent.

\section{Flow cytometry}

Peripheral blood mononuclear cells were isolated by density gradient centrifugation from blood collected into BD Vacutainer CPT Cell Preparation Tubes (BD Diagnostics, North Ryde, NSW, Australia) according to manufacturer's instructions. Peripheral blood mononuclear cells were cryopreserved until samples from all time points were available for simultaneous analysis.

Peripheral blood mononuclear cells $\left(0.5 \times 10^{6}\right)$ were stained for expression of surface markers using specific anti-human monoclonal antibodies against the following molecules: CD3 (SK7), CD4 (RPA-T4), CD8 (SK3), CD38 (HIT2), CD127 (eBioRDR5) and HLADR (L243). Staining was performed on ice for $20 \mathrm{~min}$, protected from light, in PBS with $2 \%$ heat-inactivated FCS (Life Technologies, Mulgrave, VIC, Australia), 1\% BSA (Sigma-Aldrich, Castle Hill, NSW, Australia) and $0.01 \%$ sodium azide (Sigma-Aldrich); PBS-FCS-BSA, following a $15-\mathrm{min}$ incubation at $4{ }^{\circ} \mathrm{C}$ with human FcR blocking reagent (Miltenyi Biotec, North Ryde, NSW, Australia) to prevent non-specific antibody binding. After washing, cells were fixed and permeabilised using FACS lysing solution (BD Biosciences, North Ryde, NSW, Australia) and permeabilisation solution (eBioscience, San Diego, CA, USA), then stained for intracellular marker expression using monoclonal antibodies against the following molecules: Bcl-2 (100), Ki67 (B56) and Foxp3 (206D) at RT for $30 \mathrm{~min}$, protected from light in PBS-FCS-BSA. All antibodies were purchased from BioLegend (San Diego, CA, USA), BD Biosciences or eBioscience, and were directly conjugated to FITC, PE, PECy5.5, PECy7, APC, Alexa Fluor 647 or APC-H7. Samples were stored in stabilising fixative (BD Biosciences) and analysed within $48 \mathrm{~h}$. Data were acquired using Diva software on a FACSCanto II flow cytometer (both BD Biosciences) and analysed using FlowJo software (Treestar Inc., Ashland, OR, USA). Compensation was performed post acquisition using anti-mouse Ig and anti-rabbit/hamster Ig compensation particles (BD Biosciences). T-cell populations are expressed as a proportion of the parent population.

\section{Statistical analysis}

Percentage change in the proportion of proliferating $\left(\mathrm{Ki}^{+} 7^{+}\right)$ $\mathrm{CD}^{+} \mathrm{T}$ cells as a fraction of total $\mathrm{CD}^{+} \mathrm{T}$ cells following chemotherapy was the primary outcome measure for the purpose of determining patient numbers required for this study. A change of $25 \%$ in proliferating $\mathrm{CD}^{+}{ }^{+} \mathrm{T}$ cells from baseline was considered to have potential biological significance. Forty patients were required to detect this change with $\sigma=1.1, \alpha=0.05$ and $\beta=0.8$. Three investigators (MJM, RAL, AKN) formed structured hypotheses by consensus before data was collected, to investigate the relationships between immunological endpoints and clinical outcomes. Analyses of secondary endpoints were according to these pre-determined hypotheses only; therefore, correction for multiple comparisons was not conducted.

Statistical analysis was performed using SAS version 9.2 (SAS Institute Inc., Cary, NC, USA) and GraphPad Prism version 4.0 (GraphPad Software Inc., San Diego, CA, USA). Longitudinal changes in immunological parameters were assessed using a linear mixed model. Median overall survival and TTP were estimated using the Kaplan-Meier method with groups compared using the log-rank test. Hazard ratios (HRs) were determined using the Cox proportional hazards model, after dichotomising independent immunological variables at the median value. Differences and associations were considered significant where $P<0.05$.

\section{RESULTS}

\section{Patient characteristics}

Forty-three patients with MM $(n=27)$ or NSCLC $(n=16)$ were enroled between 2007 and 2009 (Table 1). Of those with MM, 26 patients had pleural mesothelioma and 1 had peritoneal mesothelioma. Epithelioid was the predominant pleural MM subtype $(n=9 ; 35 \%)$, whereas $4(15 \%)$ had biphasic and $5(19 \%)$ had sarcomatoid disease. One patient was diagnosed with histiocytoid MM and seven (26\%) had pleural MM of unspecified histological subtype. Of the 16 patients with NSCLC, 9 (56\%) had adenocarcinoma, $5(31 \%)$ had squamous cell carcinoma and $1(6 \%)$ had bronchoalveolar NSCLC, with unspecified histological subtype in 1 case. With the exception of tumour stage, baseline characteristics were similar between patients with MM and those with NSCLC. The high proportion of patients with MM classified as stage I-III reflects the use of palliative chemotherapy for bulky nonmetastatic pleural tumour in this group. In contrast, patients with early-stage NSCLC are routinely treated with surgical resection, so were ineligible for this study. Two patients with NSCLC had previous surgery but were now being treated for advanced disease. One patient with MM had debulking surgery before chemotherapy, but tumour remained in situ.

Three patients withdrew after consenting and providing a baseline blood sample. Of the remaining 40 patients, all completed 1 treatment cycle, and 33 completed at least 3 treatment cycles (Supplementary Figure S1). Of those who completed fewer than 
Table I Patient characteristics

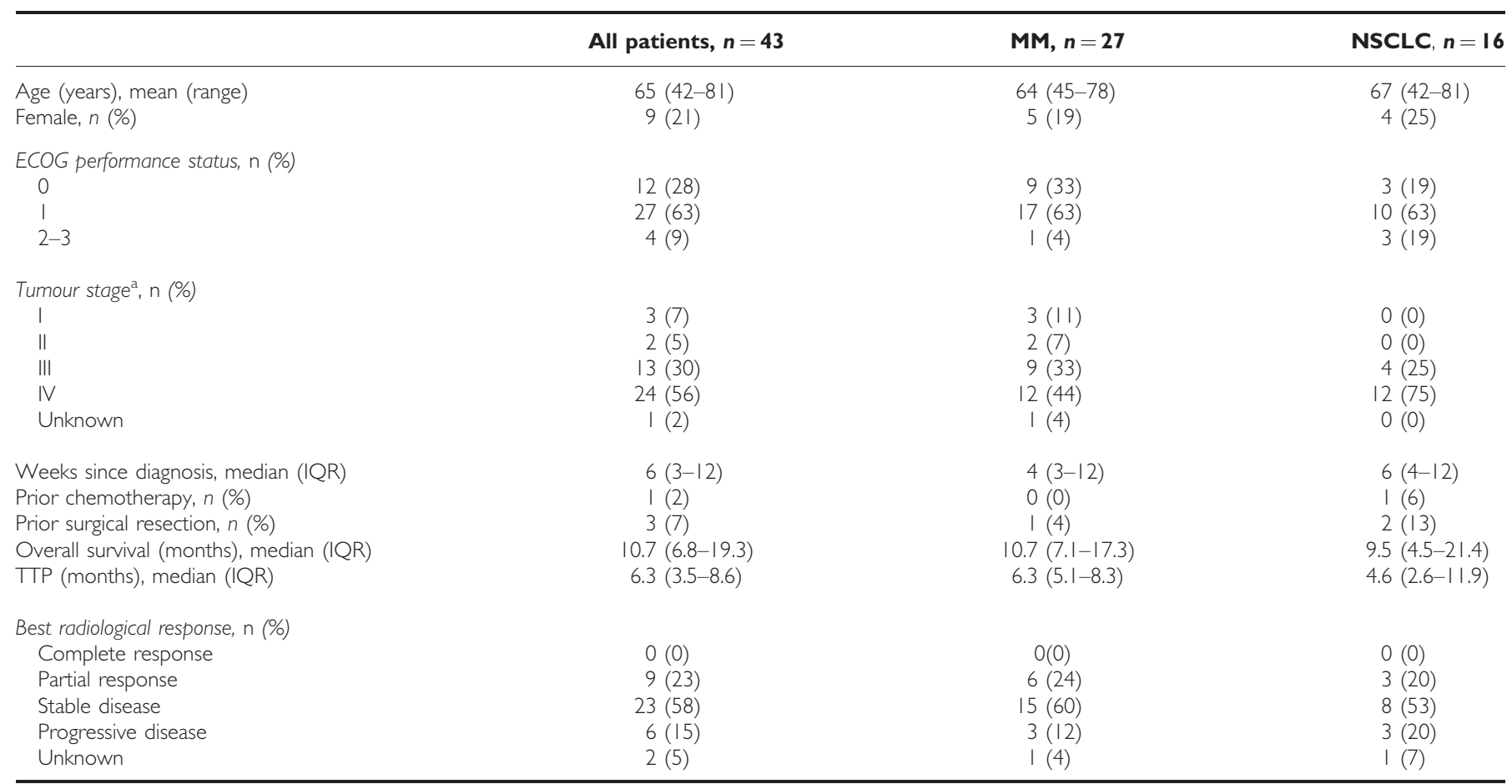

Abbreviations: $\mathrm{ECOG}=$ Eastern Cooperative Oncology Group; IQR = interquartile range; $\mathrm{MM}=$ malignant mesothelioma; NSCLC = non-small cell lung cancer; $T \mathrm{TP}=$ time to

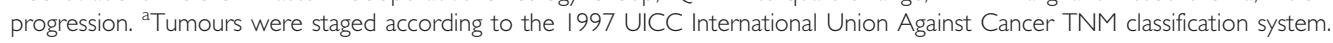

three cycles on-study, three patients died, three patients discontinued chemotherapy because of disease progression and one rural patient chose to complete treatment at a local centre. Analyses were performed using all available data from each time point. One patient was excluded from analyses because of a protocol violation (the patient was found to have taken dexamethasone continuously throughout the first treatment cycle).

Patients with MM were treated with pemetrexed plus either cisplatin $(n=19,76 \%)$ or carboplatin $(n=6,24 \%)$. The majority $(n=12,80 \%)$ of patients with NSCLC received carboplatin with gemcitabine, whereas 3 patients $(20 \%)$ were treated with carboplatin plus paclitaxel (Supplementary Table 1). All regimens consisted of 21-day cycles. Gemcitabine was administered with carboplatin on day 1 , and alone on day 8 . Drug infusion was on day 1 only for all other regimens. Cycle 1 day 8 blood samples were taken before gemcitabine infusion, where applicable. The aim of the study was to investigate longitudinal changes in T-cell subsets in patients undergoing standard platinum-based chemotherapy, not to assess specific effects of individual drugs. Therefore, data from all patients were combined for the primary analyses presented herein, after first analysing by disease/treatment group to assess the validity of this approach.

Median overall survival was 10.7 months and median TTP in all patients who received at least one chemotherapy cycle was 6.3 months; neither survival nor TTP differed between patients with MM or NSCLC (Supplementary Figure S2). No patient had a complete radiological response to treatment. Twenty-three patients $(58 \%)$ had stable disease as their best response, 9 patients $(23 \%)$ achieved a partial response, whereas 6 patients (15\%) had progressive disease on the first follow-up scan (Table 1). Two patients died before the the second-imaging time point and were not assessable for radiological response.

\section{Regeneration of T-cell subsets following chemotherapy}

Total lymphocyte numbers were significantly reduced 1 week after the first dose of chemotherapy (mean $1.50 \times 10^{9} 1^{-1}$ (baseline) $v s$
1.30 (cycle 1 day 8 ); $P<0.01$ ) and then continued to decline at a slower rate throughout the course of treatment (1.23 (post cycle 1); 1.21 (post cycle 3 ); $P<0.001$ relative to baseline; Figure $1 \mathrm{~A}$ ). This decline in total lymphocytes was similarly observed in patients with MM and NSCLC, despite the difference in treatment regimens (Figure 1B). The proportion of $\mathrm{CD}^{+} \mathrm{T}$ cells remained constant throughout chemotherapy, whereas that of $\mathrm{CD} 4{ }^{+} \mathrm{T}$ cells increased at cycle 1 day 8 (mean $41-46 \%$ of total lymphocytes; $P<0.001$ ), then returned to baseline levels by the end of each cycle (Figure 1C), consistent with previously published observations in pancreatic cancer (Plate et al, 2005). However, because of the reduction in total lymphocytes, a gradual decrease was observed in both $\mathrm{CD} 8{ }^{+}$and $\mathrm{CD} 4{ }^{+}$T-cell count during treatment (Figure 1D). Regulatory $\mathrm{T}$ cells were identified via expression of the transcription factor Forkhead box protein-3 (Foxp3) and constitutive low expression of the IL-7 receptor $\alpha$-chain, CD127 (Liu et al, 2006; Sakaguchi et al, 2010; Supplementary Figure S3B). The proportion of Foxp $3^{+} \mathrm{CD}_{12} 7^{\mathrm{lo}}$ Treg decreased significantly at cycle 1 day 8 (mean $5.8-4.8 \%$ of total $\mathrm{CD}^{+}{ }^{+} \mathrm{T}$ cells; $P<0.01$ ), returning to baseline levels by the end of cycles 1 and 3 (Figure 1E). The Treg numbers were reduced at cycle 1 day 8 , but did not decrease further with subsequent cycles (Figure 1F). CD25 expression was assessed, but not included in the gating strategy for the identification of Treg, as identifying Treg by high CD25 expression may exclude naive or 'resting' cells (Seddiki et al, 2006). These longitudinal changes in the T-cell subset proportions and counts were similarly observed in patients with MM and with NSCLC (data not shown).

The nuclear protein Ki67, expressed by cycling and recently divided lymphocytes, but not naive or resting cells (Gerdes et al, 1984; Miller et al, 2008), was used to identify proliferating $\mathrm{T}$ cells (Figure 2A, and Supplementary Figures S3B and S3C). At baseline, the median proportion of cells expressing Ki67 was 4.1\% (IQR 2.26.1) of total $\mathrm{CD}^{+}{ }^{+} \mathrm{T}$ cells, $3.8 \%(2.8-5.6)$ of total $\mathrm{CD} 4^{+} \mathrm{T}$ cells and $16.7 \%(12.0-21.8)$ of Tregs. Chemotherapy resulted in almost complete depletion of proliferating $\left(\mathrm{Ki}_{67}{ }^{+}\right) \mathrm{CD} 8^{+} \mathrm{T}$ cells, CD ${ }^{+}$ $\mathrm{T}$ cells and Tregs 1 week after treatment administration $(P<0.001$ 

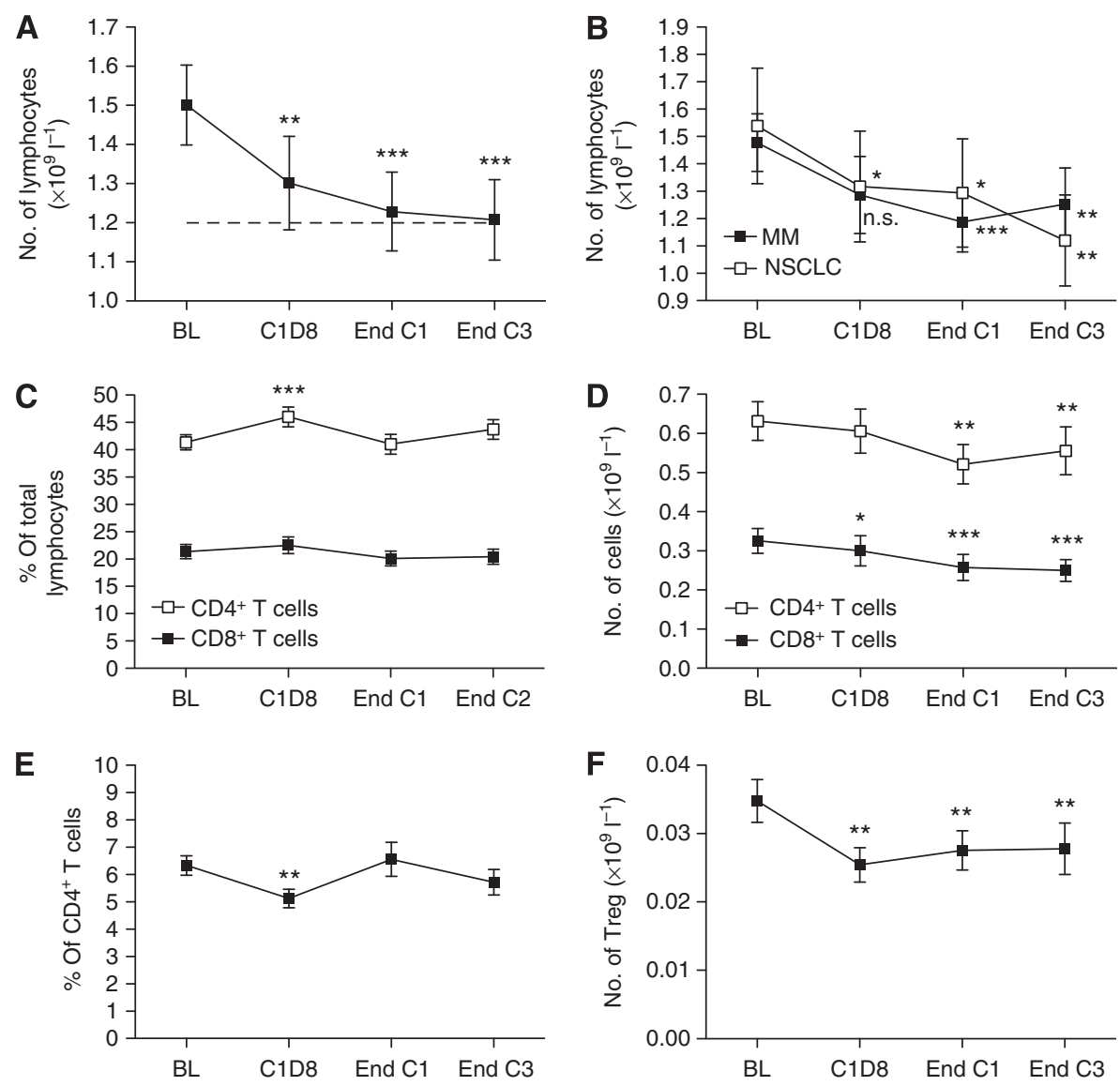

Figure I Lymphocyte counts during chemotherapy. (A) Total lymphocyte count. Broken line represents the lower limit of normal range. (B) Total

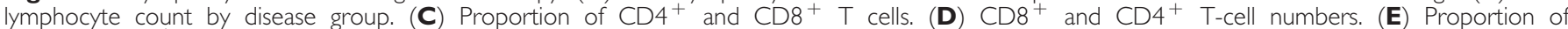
Foxp $3^{+}$CD I $27^{\text {lo }}$ Treg. (F) Treg numbers. Graphs show mean \pm s.e.m. $* P<0.05$, $* * P<0.0$ I, $* * * P<0.00$ I relative to baseline. Time points were compared using a linear mixed model. Abbreviations: $\mathrm{BL}=$ baseline; $\mathrm{CID8}=$ cycle I day 8; End $\mathrm{Cl}=$ end of cycle I; End $\mathrm{C} 3=$ end of cycle 3.

in each case). However, by the end of cycles 1 and 3, proportions of proliferating cells were significantly increased relative to baseline levels (Figure 2B-D). It is noteworthy that considerably more Tregs were $\mathrm{Ki}^{+} 7^{+}$at baseline compared with $\mathrm{CD} 8{ }^{+} \mathrm{T}$ cells or total $\mathrm{CD}^{+}{ }^{+} \mathrm{T}$ cells $(P<0.001$ in each case, Wilcoxon signed rank test $)$ as previously reported (Fisson et al, 2003; Vukmanovic-Stejic et al, 2006; Rettig et al, 2011 and Figure 2E). These results were independent of diagnosis or treatment regimen (Supplementary Figure S4 and data not shown).

As T-cell proliferation can be homeostatic or antigen-driven, surface expression of the HLA class II molecule HLA-DR and the type II transmembrane glycoprotein CD38 was assessed to identify activated effector T cells. Both HLA-DR and CD38 have frequently been described as markers of human T-cell activation (Afeltra et al, 1997; Callan et al, 1998; Pasqui et al, 2003), and, in combination, have been shown to accurately identify antigenspecific effector $\mathrm{T}$ cells following yellow fever and small pox vaccination (Miller et al, 2008). Although not usually detectable in the absence of infection or vaccination (Miller et al, 2008 and data not shown), $\mathrm{HLA}_{-} \mathrm{DR}^{+} \mathrm{CD} 38^{+}$effector $\mathrm{CD} 8^{+} \mathrm{T}$ cells were identified in patient baseline samples and at subsequent time points. These effector cells were invariably depleted at cycle 1 day 8 (Figure $3 \mathrm{~A}$ and $\mathrm{B}$ ) and recovered to baseline levels at the end of each treatment cycle, suggesting that a degree of antigen-driven T-cell activation is occurring in these patients both before and after chemotherapy. Effector $\mathrm{CD} 4{ }^{+} \mathrm{T}$-cell populations were less frequently observed, but distinguishable in some patients (data not shown). Effector $\mathrm{CD}^{+}{ }^{+}$and $\mathrm{CD} 4{ }^{+} \mathrm{T}$ cells did not express the antiapoptotic protein Bcl-2, which is constitutively expressed by resting $\mathrm{T}$ cells, but downregulated upon antigen-driven activation and thought to mediate activation-induced cell death (Grayson et al, 2000; Miller et al, 2008), providing further evidence of their activated status (Figure 3C).

\section{Change in $\mathrm{CD}^{+}{ }^{-} \mathrm{T}$-cell proliferation after one cycle of chemotherapy is predictive of survival}

Cox proportional hazards regression analyses were performed to determine whether observed changes in immunological parameters following one cycle of chemotherapy were associated with clinical outcome. Age, gender and baseline performance status, white blood cell count, haemoglobin level and platelet count were included in the regression models, as they have prognostic value in MM and NSCLC (Herndon et al, 1998; Edwards et al, 2000; Mandrekar et al, 2006; Francart et al, 2009). Immunological variables were selected according to the pre-determined hypotheses that an increase in proliferating or effector $\mathrm{CD} 8^{+} \mathrm{T}$ cells and/ or a decrease in the proportion of Tregs or proliferating Tregs would be associated with improved outcome.

A greater-than-median percentage increase in proliferating $\mathrm{CD}^{+}{ }^{+} \mathrm{T}$ cells from baseline to the end of cycle 1 predicted improved overall survival in both univariate and multivariate analyses $(\mathrm{HR}=0.40 ; 95 \% \mathrm{CI}, 0.18$ to $0.88 ; P<0.05$ and $\mathrm{HR}=0.17$; $95 \%$ CI, 0.05 to $0.56 ; P<0.01$, respectively; Table 2 ). Percentage increase in proliferating $\mathrm{CD}^{+} \mathrm{T}$ cells was also predictive of overall survival in univariate and multivariate regression when immunological variables were analysed as continuous variables $(P<0.05$ and $P<0.01$, respectively; data not shown). Median 
A
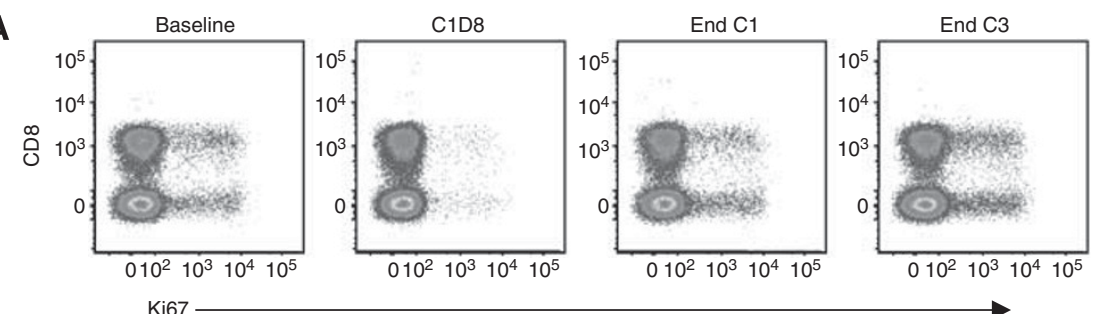

B
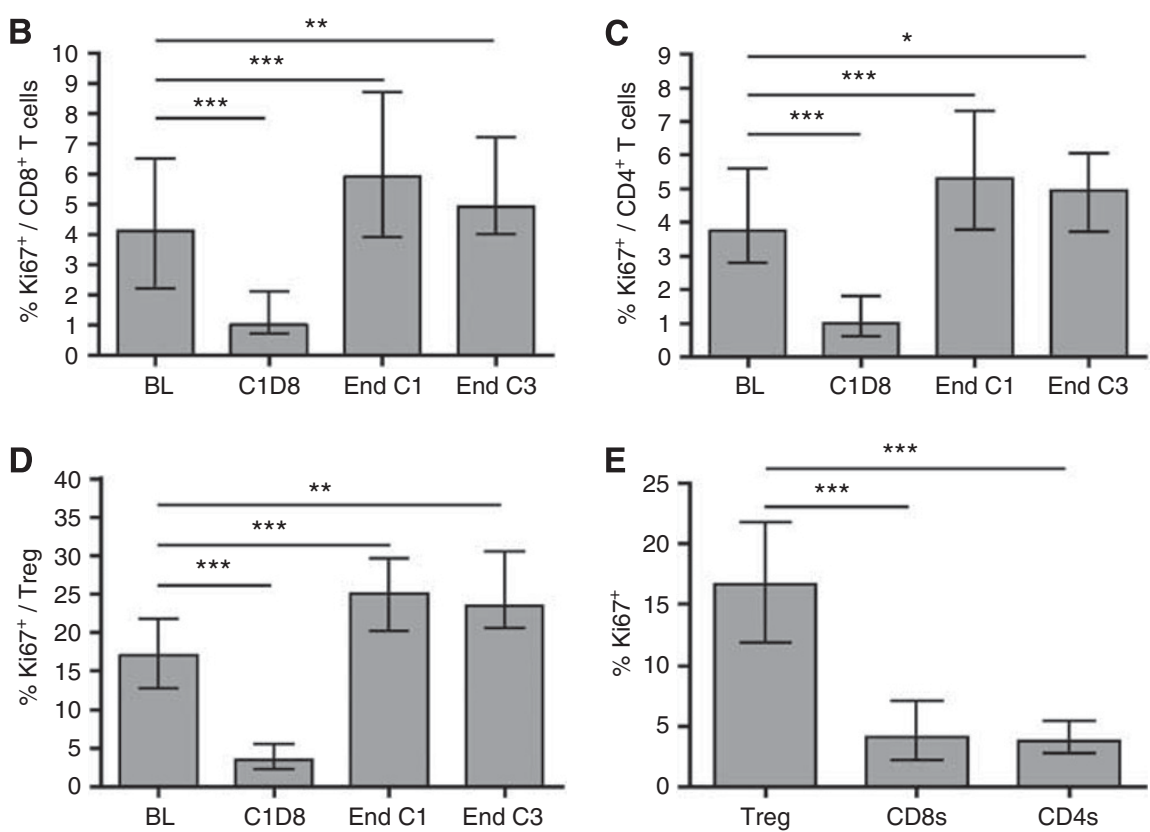

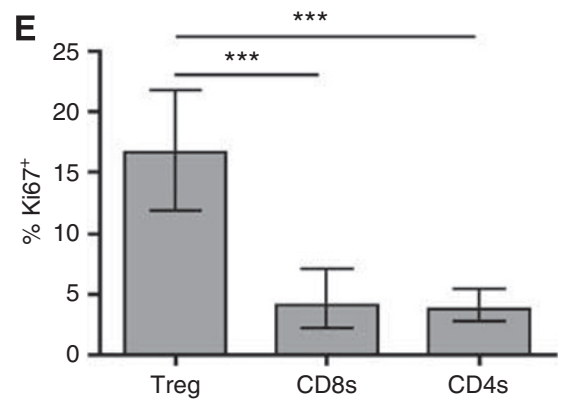

Figure 2 The effect of chemotherapy on T-cell proliferation. (A) Ki67 expression by $\mathrm{CD} 8^{+}$and $\mathrm{CD} 8^{-}\left(\mathrm{CD} 4^{+}\right) \mathrm{T}$ cells from a representative patient. Plots are gated on $\mathrm{CD}^{+}$lymphocytes. (B, C, D) Proportions of proliferating $\left(\mathrm{Ki}_{6} 7^{+}\right) \mathrm{CD}^{+} \mathrm{T}$ cells $(\mathbf{B}), \mathrm{CD} 4^{+} \mathrm{T}$ cells $(\mathbf{C})$ and Treg $(\mathbf{D})$ in all patients during chemotherapy. (E) Ki67 expression by Treg vs CD8 ${ }^{+} \mathrm{T}$ cells and total CD4 ${ }^{+}{ }^{T}$ cells in all patients at baseline. Graphs show median and IQR. Time points were compared using a linear mixed model $(\mathbf{B}, \mathbf{C}, \mathbf{D})$ and T-cell subsets using the Wilcoxon signed rank test $(\mathbf{E})$. $* P<0.05$, ***P $<0.0$ I, ****P $<0.00$ I.
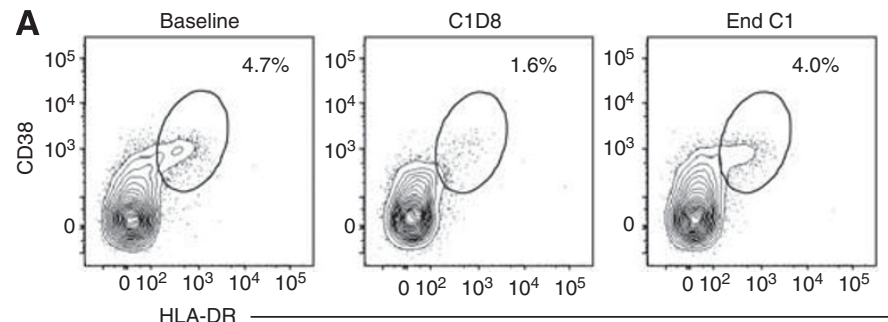

HLA-DR

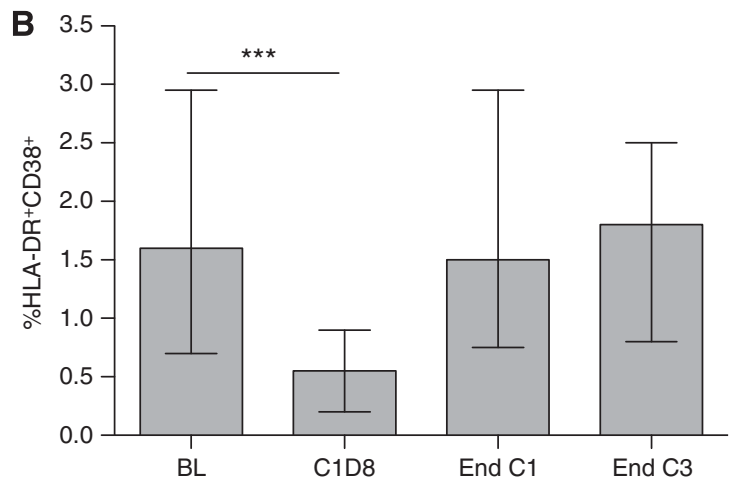

C

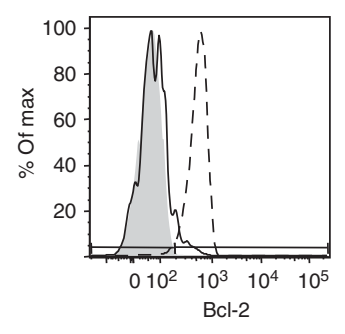

$-\mathrm{HLA}^{-\mathrm{DR}^{+} \mathrm{CD} 38^{+}}$

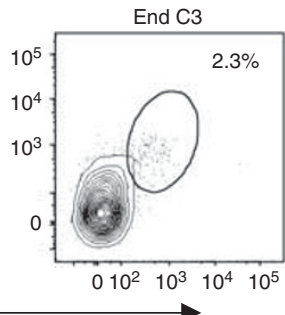

Figure 3 The effect of chemotherapy on activated effector $T$ cells. $(\mathbf{A}) \mathrm{HLA}-\mathrm{DR}{ }^{+} \mathrm{CD} 38^{+}$effector $\mathrm{CD} 8^{+} \mathrm{T}$ cells from a representative patient, values shown are percentage of total CD8 ${ }^{+}$T cells. (B) The proportion of effector CD8 ${ }^{+} T$ cells in all patients during chemotherapy. Graph shows median and interquartile range. Time points were compared using a linear mixed model; **** $P<0.00 \mathrm{I}$. (C) $\mathrm{Bcl}-2$ expression in HLA-DR ${ }^{+} \mathrm{CD} 38^{+}$effector CD8 ${ }^{+} \mathrm{T}$ cells (solid line) vs HLA-DR ${ }^{-} \mathrm{CD}_{3} 8^{-}$naive CD8 ${ }^{+} \mathrm{T}$ cells (broken line). Shaded area represents the corresponding isotype control. 
Table 2 Cox proportional hazards regression analysis of overall survival from enrolment

\begin{tabular}{|c|c|c|c|c|c|c|}
\hline & \multicolumn{3}{|c|}{ Univariate } & \multicolumn{3}{|c|}{ Multivariate } \\
\hline & HR & $95 \% \mathrm{Cl}$ & $P$ & HR & $95 \% \mathrm{Cl}$ & $P$ \\
\hline Increase in proliferating $\mathrm{CD}^{+} \mathrm{T}$ cells, large vs small & 0.40 & $0.18-0.88$ & $0.022 *$ & 0.17 & $0.05-0.56$ & $0.003 * *$ \\
\hline Increase in effector CD ${ }^{+} \mathrm{T}$ cells, large vs small & 1.03 & $0.49-2.16$ & 0.944 & 2.24 & $0.67-7.54$ & 0.193 \\
\hline Increase Treg, large vs small & 0.71 & $0.34-|.5|$ & 0.375 & 1.50 & $0.61-3.65$ & 0.375 \\
\hline Increase in proliferating Treg, large vs small & 1.00 & $0.48-2.10$ & 0.998 & 0.63 & $0.24-1.67$ & 0.354 \\
\hline Gender, male vs female & 0.49 & $0.19-1.28$ & 0.146 & 0.43 & $0.12-1.49$ & 0.181 \\
\hline Age, years & 1.01 & $0.97-1.04$ & 0.736 & 1.01 & $0.96-1.06$ & 0.691 \\
\hline ECOG status & 2.21 & $1.12-4.38$ & $0.023 *$ & 2.43 & $1.03-5.72$ & $0.043 *$ \\
\hline WBC, $\times 10^{9} 1^{-1}$ & 1.14 & $0.96-1.35$ & 0.141 & 1.16 & $0.89-1.53$ & 0.279 \\
\hline Haemoglobin, $\left.g\right|^{-1}$ & 1.00 & $0.99-1.01$ & 0.747 & 1.00 & $|.00-1.0|$ & 0.408 \\
\hline Platelets, $\times 10^{9} \mathrm{I}^{-1}$ & 1.00 & $1.00-1.00$ & 0.141 & 1.00 & $1.00-1.01$ & 0.571 \\
\hline Diagnosis, NSCLC vs MM & 0.88 & $0.42-1.84$ & 0.729 & 1.46 & $0.52-4.13$ & 0.472 \\
\hline
\end{tabular}

Abbreviations: $\mathrm{Cl}=$ confidence interval; $\mathrm{ECOG}=$ Eastern Cooperative Oncology Group; HR=hazard ratio; MM=malignant mesothelioma; NSCLC=non-small cell lung cancer; WBC = white blood cell count. All categorical covariates were transformed into numeric codes before entering into the model. Increases in immunological variables are percentage increases from baseline to the end of cycle I and were divided into large (above median increase) and small (below median increase/decrease). $* 2<0.05$. ** $P<0.01$.

A

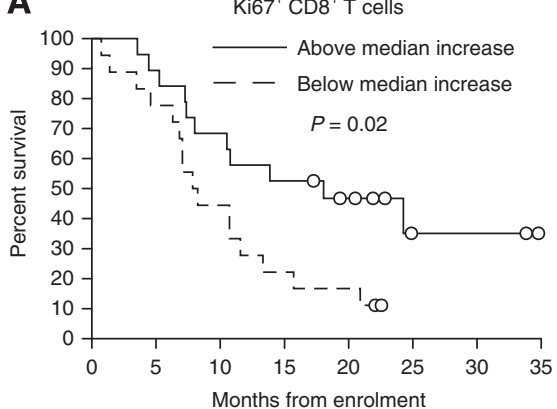

B

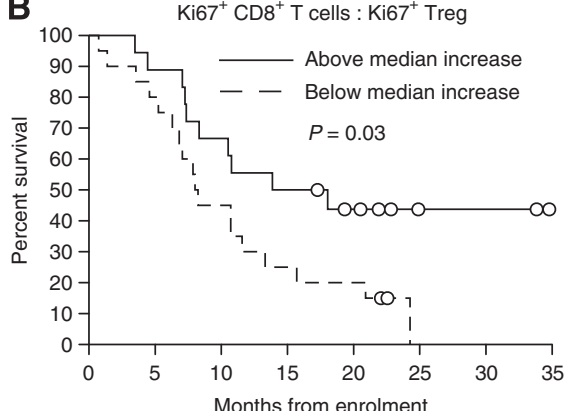

Figure 4 Change in CD8 ${ }^{+}$T cell proliferation after one cycle of chemotherapy predicts survival. Kaplan-Meier analyses of overall survival in patients with a greater-than-median increase in proliferating $\mathrm{CD}^{+}{ }^{+} \mathrm{T}$ cells $(\mathbf{A})$ or in the ratio of proliferating $\mathrm{CD} 8^{+} \mathrm{T}$ cells to proliferating Treg $(\mathbf{B})$ after one cycle of chemotherapy (solid line) vs patients with a below median increase/decrease (broken line). Groups were compared using the log rank test. Circles represent censored observations.

survival of patients with a percentage change in proliferating $\mathrm{CD}^{+} \mathrm{T}$ cells equal to or greater than $39.8 \%$ (median value) was significantly longer than that of patients with a smaller percentage increase or a decrease in proliferating $\mathrm{CD} 8{ }^{+} \mathrm{T}$ cells $(18.1$ months vs 8.1 months, respectively, $P=0.02$; Figure $4 \mathrm{~A}$ ).

As Tregs regeneration following chemotherapy was comparable to that of effector cells (Figure $2 \mathrm{~B}$ and $\mathrm{D}$ ), the ratio of proliferating $\mathrm{CD}^{+} \mathrm{T}$ cells to Tregs after one cycle of chemotherapy was also assessed. A greater percentage increase in the ratio of $\mathrm{CD} 8{ }^{+} \mathrm{T}$ cell to Tregs proliferation was also significantly associated with improved overall survival (Figure $4 \mathrm{~B}$ and Table 3). Being a composite of change in proliferating $\mathrm{CD} 8^{+} \mathrm{T}$ cells and change in proliferating Tregs, this variable was analysed in a separate multivariate model to avoid confounding through correlations in independent variables due to algebraic coupling (Archie, 1981).

Of known prognostic factors, only the ECOG performance status was a significant predictor of outcome. Although the HR for gender was 0.49 in univariate analysis, this was not statistically significant, presumably because of the small number of female participants in our study $(n=9,21 \%)$. No immunological or clinical variables were predictive of TTP or best radiological response (data not shown).

\section{DISCUSSION}

This is the first study to comprehensively investigate the longitudinal effect of chemotherapy on T-cell subsets in patients with thoracic malignancies, and to examine the relationship between changes in immunological parameters and clinical outcome. We have shown that proliferating T cells of all subsets were almost entirely depleted 1 week following treatment, but rapidly recovered with higher than baseline levels of proliferating cells at the end of each treatment cycle, representing partial regeneration of the T-cell pool. The major novel findings were that an increase in $\mathrm{CD}^{+}{ }^{+}$-cell proliferation and in the ratio of $\mathrm{CD} 8^{+}$ proliferation to Treg proliferation following one cycle of chemotherapy were positively associated with overall survival.

Depletion of proliferating cells soon after treatment administration was not unexpected, as the cytotoxic drugs used all target the actively dividing cells. The increase in T-cell proliferation observed at the end of each chemotherapy cycle most likely reflects homeostatic proliferation, driven by IL-7 and IL-15, in response to the initial lymphodepletion (Mackall et al, 1997; Schluns et al, 2000; Tan et al, 2002). However, the presence of CD8 ${ }^{+}$and CD ${ }^{+}$ $\mathrm{T}$ cells with an activated effector phenotype (HLA-DR ${ }^{+} \mathrm{CD} 38^{+}$ $\mathrm{Bcl}-2^{-}$) both before and after chemotherapy is consistent with a degree of antigen-driven activation, although the specificity of these cells is unknown. Although the increase in T-cell proliferation was not sufficient to restore $\mathrm{T}$-cell numbers to pre-treatment levels, it is consistent with the slower rate of decline in total lymphocyte count observed after cycle 1 day 8 . The effect of chemotherapy on B cells was not directly measured; however, it is noteworthy that the reduction in T-cell numbers accounted for only around $30 \%$ of the fall in lymphocyte count. As $\mathrm{T}$ cells constitute approximately $60 \%$ of the total lymphocyte pool, this is consistent with previous data demonstrating selective depletion of B cells by chemotherapy (Nowak et al, 2002; Wijayahadi et al, 
Table 3 Cox proportional hazards regression analysis of overall survival from enrolment

\begin{tabular}{|c|c|c|c|c|c|c|}
\hline & \multicolumn{3}{|c|}{ Univariate } & \multicolumn{3}{|c|}{ Multivariate } \\
\hline & HR & $95 \% \mathrm{Cl}$ & $P$ & HR & $95 \% \mathrm{Cl}$ & $\mathbf{P}$ \\
\hline Increase $\mathrm{Ki} 67^{+} \mathrm{CD} 8^{+} \mathrm{T}$ cells $: \mathrm{Ki} 67^{+}$Treg, large vs small & 0.36 & $0.16-0.78$ & $0.010 *$ & 0.29 & $0.12-0.73$ & $0.009 * *$ \\
\hline Age, years & 1.01 & $0.97-1.04$ & 0.736 & 1.01 & $0.97-1.06$ & 0.601 \\
\hline ECOG status & 2.21 & $1.12-4.38$ & $0.023 *$ & 2.45 & $1.12-5.34$ & $0.024 *$ \\
\hline WBC, $\times 10^{9} 1^{-1}$ & 1.14 & $0.96-1.35$ & 0.141 & 1.02 & $0.81-1.28$ & 0.884 \\
\hline
\end{tabular}

Abbreviations: $\mathrm{Cl}=$ confidence interval; $\mathrm{ECOG}=$ Eastern Cooperative Oncology Group; HR=hazard ratio; MM=malignant mesothelioma; NSCLC=non-small cell lung cancer; $\mathrm{WBC}=$ white blood cell count. All categorical covariates were transformed into numeric codes before entering into the model. Increase in Ki67 ${ }^{+} \mathrm{CD}^{+}{ }^{+} \mathrm{T}_{\text {cells }} \mathrm{Ki} \mathrm{K} 7^{+}$

Treg is percentage increases from baseline to the end of cycle I divided into large (above median increase) and small (below median increase / decrease). $* P<0.05$. $* * P<0.0$ I.

2007). Rather than promoting anti-tumour immune responses, tumour antigen presentation by $B$ cells can result in the tolerisation and subsequent Fas-mediated deletion of $\mathrm{CD}^{+} \mathrm{T}$ cells (Bennett et al, 1998), and B cell-deficient mice have been found to be more resistant to tumour growth than their wild-type littermates (Qin et al, 1998). Preferential B-cell depletion may therefore enhance anti-tumour immunity.

Although the proportion of total $\mathrm{CD}^{+} \mathrm{T}$ cells was slightly increased 1 week after chemotherapy administration, the percentage of Foxp $^{+} \mathrm{CD} 127^{\text {lo }}$ Tregs within this population was significantly reduced at this time point. Tregs are known to undergo rapid turnover in the steady state relative to other T-cell subsets (Fisson et al, 2003; Vukmanovic-Stejic et al, 2006; Rettig et $a l, 2011)$ as was found to be the case in the present study. Therefore, these data support the hypothesis that Tregs may be selectively depleted by cytotoxic drugs due to their increased proliferative status, as previously demonstrated using the alkylating agent cyclophosphamide (van der Most et al, 2009). It would be interesting in a future study to further characterise the effect of these chemotherapy regimens on $\mathrm{CD}^{+} \mathrm{T}$ cells by assessing changes in different T-helper subsets in light of recent observations that cyclophosphamide may promote polarisation towards Th1 and Th17 phenotypes (reviewed in Sistigu et al, 2011).

Increased proliferating $\mathrm{CD}^{+}{ }^{+} \mathrm{T}$ cells following one cycle of chemotherapy predicted improved overall survival in both univariate and multivariate analyses. The relative predictive value for change in $\mathrm{CD}^{+}$T-cell proliferation was greater than the baseline ECOG performance status, known to be strongly prognostic in both MM and NSCLC (Herndon et al, 1998; Edwards et al, 2000; Francart et al, 2009). It is of note however, that histology and tumour stage, also strongly predictive of prognosis in $\mathrm{MM}$ and NSCLC, respectively (Herndon et al, 1998; Edwards et al, 2000; Mandrekar et al, 2006; Nowak et al, 2010), could not be included in the model, as the two disease groups are not comparable with respect to these variables. Histological subtype is disease-specific, and although many patients with stage I-II MM receive palliative chemotherapy, those with stage I-II NSCLC routinely undergo potentially curative surgical resection and were ineligible for this study. Nevertheless, the majority of patients with MM in our study had stage III or IV disease. Patient numbers did not allow for regression analyses to be performed by diagnosis.

Importantly, Treg regeneration was even more pronounced than that of $\mathrm{CD}^{+} \mathrm{T}$ cells; after an initial decrease, Treg numbers remained constant, where as $\mathrm{CD}^{+} \mathrm{T}$ cell count continued to decline with subsequent cycles (Figure 1D and F). Regulatory T cell regeneration may therefore inhibit anti-tumour immunity following chemotherapy. The finding that a greater increase in the ratio of proliferating CD8 ${ }^{+} \mathrm{T}$ cells to Tregs following chemotherapy predicts improved survival suggests that the relative recovery of different T-cell subsets is indeed important. Increased tumour infiltration by $\mathrm{CD} 8^{+} \mathrm{T}$ cells and the disappearance of tumour-infiltrating Tregs after chemotherapy has been associated with better clinical outcome in breast cancer (Demaria et al, 2001; Ladoire et al, 2008). Tumour-infiltrating CD8 ${ }^{+} \mathrm{T}$ cells were also found to be a favourable prognostic factor in patients with MM who received induction chemotherapy followed by extrapleural pneumonectomy (Anraku et al, 2008). However, this is the first study, to our knowledge, to examine the relationship between change in T-cell proliferation following chemotherapy and survival. As no associations were found between changes in immunological parameters and radiological tumour response or TTP, it cannot be concluded that chemotherapy directly modulates the anti-tumour immune response rapidly or powerfully enough to enhance short-term radiological response to treatment. Instead, these results may reflect a relationship between chemotherapy and the immune system, which may subsequently impact on longer term survival rather than contribute to an immediate reduction in tumour burden. We hypothesise that chemotherapy-induced lymphodepletion may reset the stage for the induction of antitumour immunity through a temporary reduction in Tregmediated suppression early in the treatment cycle and subsequent regeneration of the T-cell pool. Tipping the balance of power in favour of $\mathrm{CD}^{+} \mathrm{T}$ cells in this post-chemotherapy immunological environment, for example, with a Treg-depleting therapy or anticancer vaccine, may lead to improved outcomes. Interestingly, dacarbazine, given 1 day before peptide vaccination was recently shown to increase the clonal repertoire of tumour antigen-specific $\mathrm{CD}^{+} \mathrm{T}$ cells and enhance memory responses in patients with resected melanoma (Nistico et al, 2009; Palermo et al, 2010).

Acknowledged weaknesses of this study include the relatively small numbers, the heterogeneous patient group, patient loss and the number of immunological hypotheses tested. However, despite small numbers, diverse regimens and different thoracic cancers, our a priori primary outcome measure was strongly associated with survival, more so than some traditional prognostic factors. These results should be validated in a larger and more uniform patient cohort. However, substantial resourcing would be required to do this even within a clinical trial due to the sample processing requirements and the labour-intensive nature of flow cytometry staining and analysis. Although preclinical studies have demonstrated that different cytotoxic agents vary in their capacity to induce immunogenic tumour cell death (Casares et al, 2005; Nowak et al, 2008), no differences were observed between patients with MM and those with NSCLC in this study, despite the use of different platinum-based chemotherapy regimens, thus supporting our decision to combine data from these two patient groups. It should also be acknowledged that dexamethasone, prescribed as an anti-emetic and/or rash prophylactic with the chemotherapy regimens used in this study, may have contributed to the observed effects on T-cell subsets. Baseline blood samples were obtained before the first dose of dexamethasone. However, as the purpose of the study was to investigate the effects of standard combination 
chemotherapy regimens used in MM and advanced NSCLC, rather than the specific effects of individual drugs, dexamethasone was considered part of the regimen and it was not stipulated that subsequent samples be taken pre-dexamethsaone.

The results of this study suggest that chemotherapy-induced lymphodepletion may actually be beneficial because of the temporary removal of Treg-mediated suppression and/or regeneration of the T-cell pool. The opportunity therefore exists to manipulate the population of newly reconstituted $\mathrm{T}$ cells with immunotherapy, to promote anti-tumour immunity. Although not predictive of short-term radiological response to treatment, change in CD8 ${ }^{+} \mathrm{T}$-cell proliferation after one cycle of chemotherapy could also represent a simple and early prognostic test for patients receiving standard chemotherapy. Changes in $\mathrm{CD}^{+}{ }^{+} \mathrm{T}$-cell proliferation should also be explored as a potential surrogate biomarker for efficacy in chemoimmunotherapy protocols.

\section{REFERENCES}

Afeltra A, Galeazzi M, Sebastiani GD, Ferri GM, Caccavo D, Addessi MA, Marcolongo R, Bonomo L (1997) Coexpression of CD69 and HLADR activation markers on synovial fluid $\mathrm{T}$ lymphocytes of patients affected by rheumatoid arthritis: a three-colour cytometric analysis. Int $J$ Exp Pathol 78(5): 331-336

Anraku M, Cunningham KS, Yun Z, Tsao MS, Tsao MS, Zhang L, Keshavjee S, Johnston MR, de Perrot M (2008) Impact of tumor-infiltrating T cells on survival in patients with malignant pleural mesothelioma. J Thorac Cardiovasc Surg 135(4): 823-829

Anraku M, Tagawa T, Wu L, Yun Z, Keshavjee S, Zhang L, Johnston MR, de Perrot M (2010) Synergistic antitumor effects of regulatory $T$ cell blockade combined with pemetrexed in murine malignant mesothelioma. J Immunol 185(2): 956-966

Archie Jr JP (1981) Mathematic coupling of data: a common source of error. Ann Surg 193(3): 296-303

Bellone G, Novarino A, Vizio B, Brondino G, Addeo A, Prati A, Giacobino A, Campra D, Fronda GR, Ciuffreda L (2009) Impact of surgery and chemotherapy on cellular immunity in pancreatic carcinoma patients in view of an integration of standard cancer treatment with immunotherapy. Int J Oncol 34(6): 1701-1715

Bennett SR, Carbone FR, Toy T, Miller JF, Heath WR (1998) B cells directly tolerize CD8 $(+)$ T cells. J Exp Med 188(11): 1977-1983

Byrne MJ, Nowak AK (2004) Modified RECIST criteria for assessment of response in malignant pleural mesothelioma. Ann Oncol 15(2): 257-260

Callan MF, Tan L, Annels N, Ogg GS, Wilson JD, O’Callaghan CA, Steven N, McMichael AJ, Rickinson AB (1998) Direct visualization of antigenspecific CD8 $+\mathrm{T}$ cells during the primary immune response to EpsteinBarr virus In vivo. J Exp Med 187(9): 1395-1402

Casares N, Pequignot MO, Tesniere A, Ghiringhelli F, Roux S, Chaput N, Schmitt E, Hamai A, Hervas-Stubbs S, Obeid M, Coutant F, Metivier D, Pichard E, Aucouturier P, Pierron G, Garrido C, Zitvogel L, Kroemer G (2005) Caspase-dependent immunogenicity of doxorubicin-induced tumor cell death. J Exp Med 202(12): 1691-1701

Demaria S, Volm MD, Shapiro RL, Yee HT, Oratz R, Formenti SC, Muggia F, Symmans WF (2001) Development of tumor-infiltrating lymphocytes in breast cancer after neoadjuvant paclitaxel chemotherapy. Clin Cancer Res 7(10): 3025-3030

Edwards JG, Abrams KR, Leverment JN, Spyt TJ, Waller DA, O'Byrne KJ (2000) Prognostic factors for malignant mesothelioma in 142 patients: validation of CALGB and EORTC prognostic scoring systems. Thorax 55(9): 731-735

Fisson S, Darrasse-Jeze G, Litvinova E, Septier F, Klatzmann D, Liblau R, Salomon BL (2003) Continuous activation of autoreactive $\mathrm{CD} 4+\mathrm{CD} 25+$ regulatory $\mathrm{T}$ cells in the steady state. $J$ Exp Med 198(5): 737-746

Francart J, Vaes E, Henrard S, Legrand C, Baas P, Gaafar R, van Meerbeeck JP, Sylvester R, Robert A (2009) A prognostic index for progression-free survival in malignant mesothelioma with application to the design of phase II trials: a combined analysis of 10 EORTC trials. Eur J Cancer 45(13): 2304-2311

Fridlender ZG, Sun J, Singhal S, Kapoor V, Cheng G, Suzuki E, Albelda SM (2010) Chemotherapy delivered after viral immunogene therapy

\section{ACKNOWLEDGEMENTS}

This study was supported by the National Health and Medical Research Council (NHMRC) and the National Centre for Asbestos Related Diseases (NCARD). MJM was funded by an International Postgraduate Research Scholarship. We thank Professors Bruce Robinson, Michael Millward, Michael Byrne and Dr Arman Hasani for their assistance with this project. We acknowledge the Australian Microscopy and Microanalysis Research Facility at the Centre for Microscopy, Characterisation and Analysis, University of Western Australia, a facility funded by the University, State and Commonwealth Governments, and we also thank Dr Kathy Heel and Tracey Lee-Pullen for their technical support.

Supplementary Information accompanies the paper on British Journal of Cancer website (http://www.nature.com/bjc)

augments antitumor efficacy via multiple immune-mediated mechanisms. Mol Ther 18(11): 1947-1959

Gerdes J, Lemke H, Baisch H, Wacker HH, Schwab U, Stein H (1984) Cell cycle analysis of a cell proliferation-associated human nuclear antigen defined by the monoclonal antibody Ki-67. J Immunol 133(4): 1710-1715 Ghiringhelli F, Larmonier N, Schmitt E, Parcellier A, Cathelin D, Garrido C, Chauffert B, Solary E, Bonnotte B, Martin F (2004) CD4 + CD25 + regulatory $\mathrm{T}$ cells suppress tumor immunity but are sensitive to cyclophosphamide which allows immunotherapy of established tumors to be curative. Eur J Immunol 34(2): 336-344

Ghiringhelli F, Menard C, Puig PE, Ladoire S, Roux S, Martin F, Solary E, Le Cesne A, Zitvogel L, Chauffert B (2007) Metronomic cyclophosphamide regimen selectively depletes $\mathrm{CD} 4+\mathrm{CD} 25+$ regulatory $\mathrm{T}$ cells and restores $\mathrm{T}$ and $\mathrm{NK}$ effector functions in end stage cancer patients. Cancer Immunol Immunother 56(5): 641-648

Grayson JM, Zajac AJ, Altman JD, Ahmed R (2000) Cutting edge: increased expression of Bcl-2 in antigen-specific memory $\mathrm{CD} 8+\mathrm{T}$ cells. J Immunol 164(8): 3950-3954

Herndon JE, Green MR, Chahinian AP, Corson JM, Suzuki Y, Vogelzang NJ (1998) Factors predictive of survival among 337 patients with mesothelioma treated between 1984 and 1994 by the Cancer and Leukemia Group B. Chest 113(3): 723-731

Ladoire S, Arnould L, Apetoh L, Coudert B, Martin F, Chauffert B, Fumoleau P, Ghiringhelli F (2008) Pathologic complete response to neoadjuvant chemotherapy of breast carcinoma is associated with the disappearance of tumor-infiltrating foxp $3+$ regulatory $\mathrm{T}$ cells. Clin Cancer Res 14(8): 2413-2420

Lake RA, Robinson BW (2005) Immunotherapy and chemotherapy-a practical partnership. Nat Rev Cancer 5(5): 397-405

Liu W, Putnam AL, Xu-Yu Z, Szot GL, Lee MR, Zhu S, Gottlieb PA, Kapranov P, Gingeras TR, Fazekas de St Groth B, Clayberger C, Soper DM, Ziegler SF, Bluestone JA (2006) CD127 expression inversely correlates with FoxP3 and suppressive function of human CD4 $+\mathrm{T}$ reg cells. J Exp Med 203(7): 1701-1711

Machiels JP, Reilly RT, Emens LA, Ercolini AM, Lei RY, Weintraub D, Okoye FI, Jaffee EM (2001) Cyclophosphamide, doxorubicin, and paclitaxel enhance the antitumor immune response of granulocyte/ macrophage-colony stimulating factor-secreting whole-cell vaccines in HER-2/neu tolerized mice. Cancer Res 61(9): 3689-3697

Mackall CL, Hakim FT, Gress RE (1997) Restoration of T-cell homeostasis after T-cell depletion. Semin Immunol 9(6): 339-346

Mandrekar SJ, Schild SE, Hillman SL, Allen KL, Marks RS, Mailliard JA, Krook JE, Maksymiuk AW, Chansky K, Kelly K, Adjei AA, Jett JR (2006) A prognostic model for advanced stage nonsmall cell lung cancer. Pooled analysis of North Central Cancer Treatment Group trials. Cancer 107(4): 781-792

Miller JD, van der Most RG, Akondy RS, Glidewell JT, Albott S, Masopust D, Murali-Krishna K, Mahar PL, Edupuganti S, Lalor S, Germon S, Del Rio C, Mulligan MJ, Staprans SI, Altman JD, Feinberg MB, Ahmed R (2008) Human effector and memory CD8 + T cell responses to smallpox and yellow fever vaccines. Immunity 28(5): 710-722

Muers MF, Stephens RJ, Fisher P, Darlison L, Higgs CM, Lowry E, Nicholson AG, O’Brien M, Peake M, Rudd R, Snee M, Steele J, Girling DJ, 
Nankivell M, Pugh C, Parmar MK (2008) Active symptom control with or without chemotherapy in the treatment of patients with malignant pleural mesothelioma (MS01): a multicentre randomised trial. Lancet 371(9625): 1685-1694

Nistico P, Capone I, Palermo B, Del Bello D, Ferraresi V, Moschella F, Arico E, Valentini M, Bracci L, Cognetti F, Ciccarese M, Vercillo G, Roselli M, Fossile E, Tosti ME, Wang E, Marincola F, Imberti L, Catricala C, Natali PG, Belardelli F, Proietti E (2009) Chemotherapy enhances vaccine-induced antitumor immunity in melanoma patients. Int J Cancer 124(1): 130-139

Nowak AK, Francis RJ, Phillips MJ, Millward MJ, van der Schaaf AA, Boucek J, Musk AW, McCoy MJ, Segal A, Robins P, Byrne MJ (2010) A novel prognostic model for malignant mesothelioma incorporating quantitative FDG-PET imaging with clinical parameters. Clin Cancer Res 16(8): 2409-2417

Nowak AK, Lake RA, Marzo AL, Scott B, Heath WR, Collins EJ, Frelinger JA, Robinson BW (2003) Induction of tumor cell apoptosis in vivo increases tumor antigen cross-presentation, cross-priming rather than cross-tolerizing host tumor-specific CD8 T cells. J Immunol 170(10): 4905-4913

Nowak AK, Mahendran S, van der Most RG, Lake RA (2008) Cisplatin and pemetrexed synergises with immunotherapy to result in cures in established murine mesothelioma. Proc Am Assoc Cancer Res Annual Meeting. (abstr 2073)

Nowak AK, Robinson BW, Lake RA (2002) Gemcitabine exerts a selective effect on the humoral immune response: implications for combination chemo-immunotherapy. Cancer Res 62(8): 2353-2358

Nowak AK, Robinson BW, Lake RA (2003) Synergy between chemotherapy and immunotherapy in the treatment of established murine solid tumors. Cancer Res 63(15): 4490-4496

Palermo B, Del Bello D, Sottini A, Serana F, Ghidini C, Gualtieri N, Ferraresi V, Catricala C, Belardelli F, Proietti E, Natali PG, Imberti L, Nistico P (2010) Dacarbazine treatment before peptide vaccination enlarges T-cell repertoire diversity of melan-a-specific, tumor-reactive CTL in melanoma patients. Cancer Res 70(18): 7084-7092

Pasqui AL, Di Renzo M, Bova G, Bruni F, Puccetti L, Pompella G, Auteri A (2003) $\mathrm{T}$ cell activation and enhanced apoptosis in non-ST elevation myocardial infarction. Clin Exp Med 3(1): 37-44

Plate JMD, Plate AAE, Shott S, Bograd S, Harris JE (2005) Effect of gemcitabine on immune cells in subjects with adenocarcinoma of the pancreas. Cancer Immunol Immunother 54(9): 915-925

Qin Z, Richter G, Schuler T, Ibe S, Cao X, Blankenstein T (1998) B cells inhibit induction of $\mathrm{T}$ cell-dependent tumor immunity. Nat Med 4(5): 627-630

Rettig L, Seidenberg S, Parvanova I, Samaras P, Knuth A, Pascolo S (2011) Gemcitabine depletes regulatory $\mathrm{T}$-cells in human and mice and enhances triggering of vaccine-specific cytotoxic T-cells. Int $\mathrm{J}$ Cancer 129(4): 832-838

Sakaguchi S, Miyara M, Costantino CM, Hafler DA (2010) FOXP3 + regulatory $\mathrm{T}$ cells in the human immune system. Nat Rev Immunol 10(7): 490-500

Scagliotti GV, Parikh P, von Pawel J, Biesma B, Vansteenkiste J, Manegold C, Serwatowski P, Gatzemeier U, Digumarti R, Zukin M, Lee JS, Mellemgaard A, Park K, Patil S, Rolski J, Goksel T, de Marinis F, Simms L, Sugarman KP, Gandara D (2008) Phase III study comparing cisplatin plus gemcitabine with cisplatin plus pemetrexed in chemotherapy-naive patients with advanced-stage non-small-cell lung cancer. J Clin Oncol 26(21): 3543-3551

Schiller JH, Harrington D, Belani CP, Langer C, Sandler A, Krook J, Zhu J, Johnson DH (2002) Comparison of four chemotherapy regimens for advanced non-small-cell lung cancer. N Engl J Med 346(2): 92-98

Schluns KS, Kieper WC, Jameson SC, Lefrancois L (2000) Interleukin-7 mediates the homeostasis of naive and memory CD8 $\mathrm{T}$ cells in vivo. Nat Immunol 1(5): 426-432

Seddiki N, Santner-Nanan B, Tangye SG, Alexander SI, Solomon M, Lee S, Nanan R, Fazekas de Saint Groth B (2006) Persistence of naive CD45RA + regulatory T cells in adult life. Blood 107(7): 2830-2838

Sistigu A, Viaud S, Chaput N, Bracci L, Proietti E, Zitvogel L (2011) Immunomodulatory effects of cyclophosphamide and implementations for vaccine design. Semin Immunopathol 33(4): 369-383

Tan JT, Ernst B, Kieper WC, LeRoy E, Sprent J, Surh CD (2002) Interleukin (IL)-15 and IL-7 jointly regulate homeostatic proliferation of memory phenotype $\mathrm{CD} 8+$ cells but are not required for memory phenotype CD4 + cells. J Exp Med 195(12): 1523-1532

Therasse P, Arbuck SG, Eisenhauer EA, Wanders J, Kaplan RS, Rubinstein L, Verweij J, Van Glabbeke M, van Oosterom AT, Christian MC, Gwyther SG (2000) New guidelines to evaluate the response to treatment in solid tumors. European Organization for Research and Treatment of Cancer, National Cancer Institute of the United States, National Cancer Institute of Canada. J Natl Cancer Inst 92(3): 205-216

Tseng CW, Hung CF, Alvarez RD, Trimble C, Huh WK, Kim D, Chuang CM, Lin CT, Tsai YC, He L, Monie A, Wu TC (2008) Pretreatment with cisplatin enhances E7-specific CD8 + T-cell-mediated antitumor immunity induced by DNA vaccination. Clin Cancer Res 14(10): 3185-3192

van der Most RG, Currie AJ, Mahendran S, Prosser A, Darabi A, Robinson BW, Nowak AK, Lake RA (2009) Tumor eradication after cyclophosphamide depends on concurrent depletion of regulatory $\mathrm{T}$ cells: a role for cycling TNFR2-expressing effector-suppressor $\mathrm{T}$ cells in limiting effective chemotherapy. Cancer Immunol Immunother 58(8): 1219-1228

Vogelzang NJ, Rusthoven JJ, Symanowski J, Denham C, Kaukel E, Ruffie P, Gatzemeier U, Boyer M, Emri S, Manegold C, Niyikiza C, Paoletti P (2003) Phase III study of pemetrexed in combination with cisplatin versus cisplatin alone in patients with malignant pleural mesothelioma. J Clin Oncol 21(14): 2636-2644

Vukmanovic-Stejic M, Zhang Y, Cook JE, Fletcher JM, McQuaid A, Masters JE, Rustin MH, Taams LS, Beverley PC, Macallan DC, Akbar AN (2006) Human CD4 + CD25hi Foxp3 + regulatory T cells are derived by rapid turnover of memory populations in vivo. J Clin Invest 116(9): 2423-2433

Wijayahadi N, Haron MR, Stanslas J, Yusuf Z (2007) Changes in cellular immunity during chemotherapy for primary breast cancer with anthracycline regimens. J Chemother 19(6): 176-723

Zhong H, Han B, Tourkova IL, Lokshin A, Rosenbloom A, Shurin MR, Shurin GV (2007) Low-dose paclitaxel prior to intratumoral dendritic cell vaccine modulates intratumoral cytokine network and lung cancer growth. Clin Cancer Res 13(18): 5455-5462

Zitvogel L, Kepp O, Senovilla L, Menger L, Chaput N, Kroemer G (2010) Immunogenic tumor cell death for optimal anticancer therapy: the calreticulin exposure pathway. Clin Cancer Res 16(12): 3100-3104

This work is published under the standard license to publish agreement. After 12 months the work will become freely available and the license terms will switch to a Creative Commons Attribution-NonCommercial-Share Alike 3.0 Unported License. 